\title{
Systematic Reviews and Meta-Analyses
}

\section{Efficacy and knowledge of conducting CPR through online learning during the COVID-19 pandemic: A literature review}

\author{
Iil Dwi Lactona, Suryanto \\ School of Nursing, Faculty of Medicine, University of Brawijaya, Malang, Indonesia
}

\begin{abstract}
The COVID-19 pandemic has made it difficult to carry out face-to-face training activities in various higher institutions. This has led to a negative impact on the skills and abilities of nursing students in performing cardiopulmonary resuscitation (CPR) and the cessation of their clinical practice programs in hospitals. Therefore, the aim of this study is to determine the efficacy and knowledge of nursing students in performing CPR by implementing a blended learning program, through online learning platforms. The search for full-text articles was carried out in May 2020 and were reviewed to know whether they fit the theme using the ProQuest, ScienceDirect and PubMed databases with the keywords "BLS", "CPR", "Blended learning", "Knowledge" and "Self-efficacy". In addition, there were 15 articles that matched the criteria. The application of a blended learning program that integrates video and face-to-face lectures through online learning platforms in conducting effective CPR, increases the efficacy and knowledge of nursing students. The effectiveness of online learning greatly affects the efficacy and knowledge of nursing students in conducting CPR. Therefore, it was highly recommended during the COVID-19 pandemic.
\end{abstract}

\section{Introduction}

When not properly managed, cardiac arrest may lead to permanent brain damage and eventually death due to reduced blood flow. Cardiopulmonary resuscitation (CPR) is a technique used to resuscitate someone that has a sudden heart attack. This is carried out by either performing breathing assistance or giving oxygen to the lungs and chest compressions to drain blood until the heart rate and breathing returns to normal state and medical assistance arrives. ${ }^{1} \mathrm{CPR}$ is defined as a life-saving emergency procedure that combines both artificial ventilation and chest compressions to maintain a stable blood circulation to the brain during the event of a sudden cardiac arrest. However, recent studies have shown that the survival rates remained low at $11.4 \%$ for outpatient heart attacks and $23.8 \%$ for hospital heart attacks, even when CPR pro- cedures were applied. ${ }^{2}$

The COVID-19 pandemic, which started in Wuhan, China at the end of 2019, is a deadly virus that attacks the respiratory system and is transmitted rapidly through physical contact and air. This pandemic has caused a negative impact to all countries all over the world, especially with the implementation of a regional lockdown status where community activities are hampered. This has affected government institutions, private companies, entrepreneurship, transportation, tourism, education, and many other sectors. ${ }^{3,4}$ The COVID-19 pandemic has brought about changes in the various aspects of life, especially in the field of education where learning needs to be conducted frequently and updated. Furthermore, lessons that were once conducted physically in the classroom are now being taught on virtual meetings online to prevent further spread of the virus. Everyone is expected to adapt to the use of modern technology and the industrial revolution 4.0, especially for both educators and students. ${ }^{4}$

$\mathrm{CPR}$ training and its quality are critical in increasing the rate of surviving heart attack. In preparation for clinical practice at the hospital, students are required to have competent basic life support (BLS) especially of conducting CPR. However, the COVID-19 pandemic has led to the implementation of lockdowns and maintaining social distancing to prevent the spread of the virus. This affected the ability of nursing students to conduct CPR due to inadequate manual training. ${ }^{2,5,6}$ Therefore, guidance from professional societies and biomedical ethicists about how and when to perform CPR is needed. Some extreme views on this topic have already emerged, including calls for a universal do-not-resuscitate policy for patients infected with COVID-19. It is necessary to have learning innovations and participate in creative discussions, through various learning media applications in order for learning activities to run smoothly in a sustainable manner and with fun. ${ }^{7}$

A study conducted in Armenia shows that tele-education is effective and beneficial when applied in developing countries. In this study, it was also stated that there was a significant increase in the assessment of knowledge after the lecture ended. Therefore, this new method of learning is considered very important, valuable, understandable, easy, and applicable to nurses that have never been previously been exposed to it. The virtual reality (VR)

Significance for public health

The use of information and communication technology during the COVID-19 pandemic and the development of the industrial era 4.0, made the learning and training process more innovative. Various online learning methods were carried out to support educational processes in order to achieve competency. Furthermore, the use of blended learning-based application media, has made it possible for students and trainers to easily access training materials and interact with each other using computers via the internet network. This is the first study to examine the efficacy and knowledge of performing CPR through online learning during the COVID-19 pandemic. The findings regarding the latest learning innovations for nursing students were useful in relation to the discourse and means of learning clinical practices in hospitals and the formation of competent nursing students. 
technology also makes it possible to conduct online training by implementing virtual three-dimensional CPR procedures. This would improve the skills and knowledge of nursing students compared to face-to-face training. , $^{, 7}$

Based on the above benefits provided from using online learning methods, the purpose of this study is to determine the efficacy and knowledge of nursing students in performing CPR procedures by implementing a blended learning program through online learning platforms during the COVID-19 pandemic.

\section{Methods}

This study was conducted according to the PRISMA guidelines, and the data-based literature search was carried out in May 2020 in which the articles selected were of repute. They were limited from the published year 2010 to 2020 and reviewed systematically to obtain empirical evidence regarding the efficacy and knowledge of performing CPR through online learning. Search engines such as ProQuest, ScienceDirect and PubMed were used during the literature research. This was carried out by using a keyword combination "BLS", "CPR", "Blended learning", "Knowledge" and "Self-efficacy" with Boolean search methods such as the "AND", "OR" and "NOT" to get related articles that meet the objectives of the literature review.

The determination of the inclusion and exclusion criteria was based on the PICOS (population, intervention, comparators, outcomes and study design) method which was adjusted to the meet the objectives of the literature review. The determination of the inclusion and exclusion criteria are shown in Table 1. Based on the results from the literature searches through publications in three databases, 745 articles were found that matched the keywords used. Furthermore, after checking for duplication, about 112 articles had similar contents and were excluded, leaving a total of 633 remaining. They were further screened based on the title and abstract and 165 articles that meant the purpose were obtained. Furthermore, they were screened based on full text, which resulted to 74 suitable articles. The feasibility assessment of the 74 articles were based on the overall text and conformity with the eligibility criteria. Therefore, 66 articles were not suitable and only 15 could be used in the literature review. The results of the study selection are illustrated in a flowchart using the PRISMA selection process in Figure 1. Information was also extracted from the 15 articles in the form of authors, research objectives, population selection, intervention selection, research design, data analysis techniques, educational content, samples, year of publication, and the language used from each study according to the research objectives.

\section{Results and Discussions}

The results from the review of the 15 articles are related to the efficacy and knowledge of performing CPR through online learning and the articles were published from 2010 to 2020 . The articles were experimental studies, namely a randomized controlled trial $(73,33 \%, 11 / 15)$, a quasi-experiment $(13.33 \%, 2 / 15)$, and non-inferiority trial $(13.33 \%, 2 / 15)$. The number of samples from the articles found ranged from 41 to 50,000 samples with a total of 71,332. It was observed that there was a positive effect on the efficacy and knowledge of performing CPR through online learning (Table 2).

CPR is an important procedure in the event of a sudden cardiac arrest in order for the patient to survive. This process is usually carried out with the assistance of breathing and chest compressions. Structured training in increasing self-efficacy, knowledge and performance that was normally conducted during faceto-face learning in classes was constrained by the COVID-19 pan-

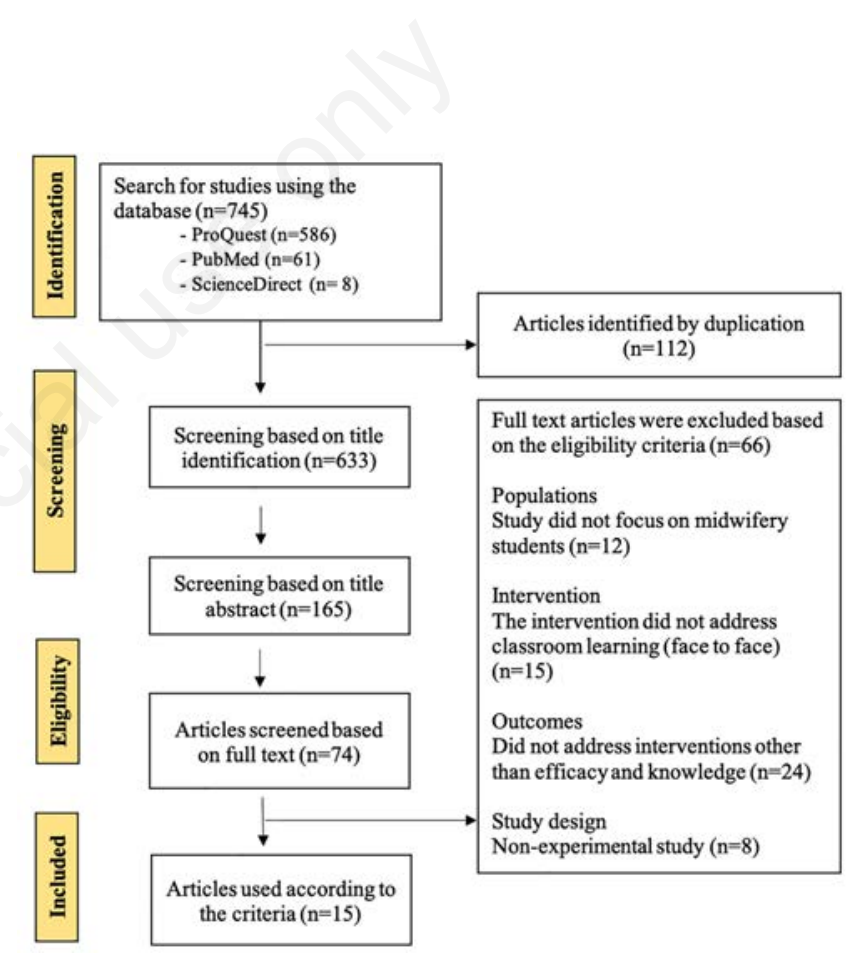

Figure 1. Flowchart of literature review with selection process using PRISMA.

Table 1. Inclusion and exclusion criteria.

\begin{tabular}{lll} 
Criteria & Inclusion & Exclusion \\
P & Studies that focused on nursing students & Besides nursing students (midwifery students) \\
I & $\begin{array}{l}\text { Studies that addressed the efficacy and knowledge } \\
\text { of performing online CPR }\end{array}$ & Studies that do not address classroom learning (face to face) \\
\hline C & Studies with control or comparison intervention groups & There were no exclusion criteria \\
O & The study that explained the effect of the efficacy and & Other interventions apart from efficacy and knowledge \\
\hline S & Enowledge of performing CPR through online learning & \\
\hline P, population; I, intervention; C, comparators; 0, outcomes; $S$, study design; CPR, cardiopulmonary resuscitation.
\end{tabular}


Table 2. Summary on the efficacy and knowledge of doing cardiopulmonary resuscitation through online learning in the COVID-19 pandemic.

\begin{tabular}{|c|c|c|}
\hline Author & $\begin{array}{l}\text { Number of } \\
\text { samples }\end{array}$ & $\begin{array}{l}\text { Research } \\
\text { design }\end{array}$ \\
\hline
\end{tabular}

Boada et al. 109 samples $\quad$ Randomized

controlled trial

Wong et al. ${ }^{2} \quad 30$ samples $\quad$ Randomized controlled trial

Moon and Hyun ${ }^{9} \quad 120$ samples $\quad$ Randomized controlled trial

Na et al. ${ }^{12} \quad 2,169$ samples Prospective cluster randomized study

Park et al. ${ }^{13} \quad 79$ samples Quasi-experimentation

$\begin{array}{lrl}\text { Cheng et al. } .^{14} & 832 \text { samples } & \text { Randomized controlled non-inferiority trial } \\ & \text { Drummond et al. }{ }^{15} 82 \text { samples } & \text { Randomized controlled trial }\end{array}$

Drummond et al. ${ }^{15} 82$ samples $\quad$ Randomized controlled trial

\begin{tabular}{lll} 
Napp $^{17}$ & 808 samples & Randomized, controlled, non-inferiority trial \\
& & \\
\hline Nord et al. ${ }^{18}$ & 432 samples & Randomized controlled trial
\end{tabular}

Boada et a $l^{20} \quad 41$ samples Quasi-experimentation

Tobase et al. ${ }^{21} \quad 94$ samples $\quad$ Randomized controlled trial

Twohig et al. ${ }^{22} \quad 948$ samples Randomized controlled trial

Lau et al. ${ }^{23} \quad 15.528$ samples Randomized controlled trial

\begin{tabular}{|c|c|c|c|}
\hline Zhou et al. ${ }^{24}$ & 60 samples & Randomized controlled trial & $\begin{array}{l}\text { Compared with the traditional teaching methods, the effect of combined mode of MOOC } \\
\text { micro-video in emergency nursing practice especially doing CPR is the same as that of } \\
\text { traditional teaching methods, but the satisfaction is higher, so it is more suitable to be used } \\
\text { in nursing practice during the COVID-19 epidemic period, so as to effectively reduce the } \\
\text { cross-infection between doctors, nurses, and teaching staff. }\end{array}$ \\
\hline Nas et al. ${ }^{26}$ & 50.000 samples & Randomized controlled trial & $\begin{array}{l}\text { The Lowlands Saves Lives trial will create awareness for the importance of bystander CPR } \\
\text { and aims to increase willingness and capability to participate in CPR that important insights } \\
\text { into the efficacy of innovative CPR training methods which may help to improve CPR skills of } \\
\text { lavperson rescuers, with the ultimate goal of improving outcomes after cardiac arrest. }\end{array}$ \\
\hline
\end{tabular}

CPR, cardiopulmonary resuscitation; VR, virtual reality; BLS, basic life support; AMI, acute myocardial infarction.
Learning using the game Life Support Simulation Activities (LISSA)

which implements 3D virtual games in conducting CPR training was much more interesting and increases student knowledge and efficacy compared to traditional classroom learning.

The study highlighted gaps in current health professionals' CPR education that could be addressed using VR-enabled learning and assessment activities. CPR instructors identified fidelity, engagement, resource conservation, and memory enhancement as features of VR that make it ideal for health profe sionals' CPR education. Virtual reality was viewed by CPR instructors as having potential as a blended learning tool, targeting both 'novice' and 'experienced' health professionals.

The CPR blended learning program that integrates video and face-to-face lectures was effective in enhancing the knowledge and attitudes of nursing students.

The small group discussion (SGD) renewal program was more effective than the practice while watching the PWW program in increasing the knowledge and skills in BLS renewal training.

Blended E-learning, with self-directed repetitive learning, was more effective in improving nursing competence, self-efficacy, problem solving, and psychomotor skills for cardiopulmonary resuscitation and defibrillation than conventional practical education.

Mixed CPR training programs are not inferior to the ones done traditionally in that compression depth was the primary outcome. While CPR knowledge, practicality, quality of CPR performance, and skills retention were secondary outcomes.

The serious games used in the study were not superior to the online courses used in training medical students in the management of heart attacks. The absence of a correlation between evaluated student performance during two training sessions separated by 4 months suggests that elements such as chest compressions could only be studied with simulation based training.

Online education is an effective alternative for preparing prospective BLS instructors. By using free online courses, people that are motivated could independently acquire the skills necessary to become instructors and realize low-cost BLS training in schools.

A web course before CPR training did not influence practical CPR skills or willingness to act, but improved the students' theoretical knowledge of AMI, stroke and lifestyle factors. Virtual simulation using different scenarios is an appropriate strategy for practicing car diopulmonary resuscitation procedures in a safe and risk-free manner for the patient, there by improving CPR performance.

The online course was an effective method for teaching and learning key BLS skills wherein students were able to accurately apply BLS procedures during the CPR simulation. This short-term online training, which likely improves learning and self-efficacy in BLS providers, can be used for the continuing education of health professionals.

ECPR is a sophisticated treatment option which may improve outcomes in a selected patient population in refractory cardiac arrest. Further comparative research is needed clarify the role of this potential resuscitative therapy.

Meta-analyses revealed that trainees in digital resuscitation training had better knowledge scores but poorer chest compression rates than that of trainees in standard resuscitation training. Digital resuscitation trainings were non-inferior to standard resuscitation trainings in skill performance scores. Subgroup analyses suggested that digital resuscitation training might consider using blended learning approach with virtual patient, computer-screen based, learning theories and video-recorded assessment, especially for basic life support trainings amongst health professionals.

Compared with the traditional teaching methods, the effect of combined mode of MOOC Cricro-video in emergency nursing practice especially doing CPR is the same as that of in nursing practice during the COVID-19 epidemic period, so as to effectively reduce the cross-infection between doctors, nurses, and teaching staff.

and aims to increase willingness and capability to participate in CPR that important insights ayperson rescuers, with the ultimate goal of improving outcomes after cardiac arrest. 
demic. This made people carry out social distancing in order to prevent further spread of the virus. ${ }^{8,9}$ Online learning-based education was carried out to improve the skills and abilities of nursing students in performing CPR even though it was done remotely. ${ }^{8}$ Factors that affect the efficacy and knowledge of performing CPR through online learning include difficulty to simulate the correct performance of the procedure, the compression rhythm and depth are difficult to realistically assess, and the ventilation provided is difficult to simulate. ${ }^{10}$ Then analyzing the effects of online learning in performing CPR on the efficacy and the knowledge of nursing students, there was an increase in their skills and simulation via video and web-based lectures. This learning method makes it easier for students to follow because of the flexibility of space and time compared to direct training. In addition, online learning methods attract young people and should be used as a means of training. ${ }^{9}, 10$

According to Akhu-Zaheya et al., ${ }^{11}$ self-efficacy could be obtained, changed, increased or decreased through several sources, due to performance accomplishment, social persuasion and emotional states. In an empirical research, it was proven that self-efficacy is still a major predictor of success in online learning compared to traditional face-to-face learning in classes. Furthermore, the small group discussion (SGD) renewal program was more effective than watching the (PWW) program. ${ }^{12}$

Based on the research statement by Park, ${ }^{13}$ blended E-learning with self-directed repeated learning is more effective in improving nursing competence, self-efficacy, problem solving, and psychomotor skills for cardiopulmonary resuscitation and defibrillation. Rather than conventional practical education. This is similar to a research conducted by Moon and Hyun, ${ }^{9}$ on 120 respondents, using the CPR blended learning program method that integrates video and face-to-face lectures effectively in increasing the knowledge and attitudes of nursing students. Effective training involving emergency treatment through online learning is very effective and affects the self-efficacy, knowledge, problem solving and actual clinical practice performance skills required by nurses. ${ }^{13}$ This is in line with Chien and colleagues' research, which states that the mixed CPR training program is not inferior to the ones done traditionally, and integrates online learning and simulation in order for assessment of compression depth, CPR knowledge, practicality, quality of CPR performance, and skill retention becomes a significant result. ${ }^{14}$

Many online learning methods were carried out using alternative electronic media applications and games to support competencies that need be achieved due to the COVID-19 pandemic. Simulation-based training that using online games were also used in learning CPR procedures. This is in line with research from Boada et al., ${ }^{1}$ in which learning was carried out using the game Life Support Simulation Activities (LISSA), which works on 3D virtual games in conducting CPR training. It was able to increase student's knowledge and efficacy compared to traditional classroom learning. ${ }^{1}$ In addition, Drummond et al. also stated that the online method with simulation-based training games was more superior to use. ${ }^{15}$ Virtual simulation using scenarios could be an appropriate strategy for practicing cardiopulmonary resuscitation (CPR) procedures in a safe and risk-free manner for the patient, thereby improving CPR performance. ${ }^{16}$
The success of the CPR procedure was supported by good comprehensive training facilities through online learning because of the advantages of it being more practical, and professionals find it more flexible to use. A research conducted by Napp and colleagues showed that preparing BLS instructors with online learning was more effective than face-to-face training in class. ${ }^{17}$ In Nord and co-authors' study, an interactive web course using elearning simulation software preparation by a health care provider does not improve practical CPR skills, but knowledge about increasing knowledge of acute myocardial infarction (AMI), stroke and lifestyle factors; this learning flexibility is seen in terms of location and time and cost. ${ }^{18}$ Factors that influence selfefficacy in online learning experiences are age, level of education, and experience. ${ }^{19}$ The study by Boada et al. ${ }^{20}$ evaluates how characteristics of the sex of the victim in a scenario designed to practice cardiopulmonary resuscitation protocol (CPR) affected performance student nurses, the result is a virtual scenario can be an appropriate strategy to reduce gender differences in gender sensitive situations such as CPR performance. Online learning is an effective method for learning-teaching skills where students BLS able to apply the BLS procedure accurately during CPR simulation. According to AHA, preparation and qualification resolution assistance significantly affects success resuscitation and increase the chances of survival. ${ }^{21}$ In line with Twohig et al.'s study, reviewing evidence comparing ECPR results with conventional CPR (CCPR), before examining resuscitation-specific parameters to assess patient. Where are the results ECPR is a sophisticated treatment option that can improve outcomes in certain patient populations in refractory heart attack. ${ }^{22}$

Subgroup analysis is suggested that digital resuscitation training may consider using a mixed learning approach with virtual patients, computer screen-based, video-based learning theory and assessment, especially for CPR training among health professionals. ${ }^{23}$ In Zhou et al.'s ${ }^{24}$ research, the practice of teaching distance using Combined Mode Massive Open Micro-Video Course for student interns in the Department of Emergencies During the Epidemic Period the COVID-19 states the combined mode effect of the MOOC micro-video in emergency nursing practice is the same as the traditional effect teaching method, but higher satisfaction. ${ }^{24}$ The critical role of repetitive periodic CPR training courses to ensure that nurses were competent, up to date and confident responders in the event of a cardiac arrest is present strong evidence to support practice of nursing in the emergency life-saving procedure of CPR. ${ }^{25}$

\section{Conclusions}

The simulation technique in the procedures for performing CPR is very important in conducting online lessons. Furthermore, learning about the principles and skills of the nursing care plan increases the efficacy, knowledge, attitudes and appropriate clinical experience for nursing students to become competent practitioners. Following the 4.0 technology era and the COVID-19 pandemic all aspects of life need to change by implementing online learning to prevent further spread of the virus. 
Correspondence: Iil Dwi Lactona, Magister of Nursing, Faculty of Medicine, University of Brawijaya Jl. Puncak Dieng, Kunci, Kalisongo, Kecamatan Dau, Malang, East Java, Indonesia 65151. Tel. +62.341569117 - Fax: +62.3241564755.

E-mail: ilmayraqueen@student.ub.ac.id

Acknowledgment: The author is grateful to the Faculty of Medicine, University of Brawijaya Malang, Malang, Indonesia for their kind support and encouragements during this study.

Key words: BLS; CPR; online learning; knowledge; self-efficacy.

Contributions: All authors contributed equally to this study. It was conducted and supervised by IDL and S.

Conflict of interest: The authors declare no potential conflict of interest.

Funding: This study received no specific grant from any funding agency in the public, commercial, or non-profit sectors.

Conference presentation: Part of this study was presented at the $1^{\text {st }}$ International Nursing and Health Sciences Symposium, November $13^{\text {th }}$ to $15^{\text {th }} 2020$, Brawijaya University, Malang, Indonesia.

Received for publication: 14 January 2021.

Accepted for publication: 15 March 2021.

(Copyright: the Author(s), 2021

Licensee PAGEPress, Italy

Journal of Public Health Research 2021;10:2208

doi:10.4081/jphr.2021.2208

This work is licensed under a Creative Commons Attribution NonCommercial 4.0 License (CC BY-NC 4.0).

\section{References}

1. Boada I, Rodriguez-Benitez A, Garcia-Gonzalez JM, et al. Using a serious game to complement CPR instruction in a nurse faculty. Comput Methods Programs Biomed 2015;122:282-91.

2. Wong MA, Chue S, Jong M, et al. Clinical instructors 'perceptions of virtual reality in health professionals' cardiopulmonary resuscitation education. SAGE Open Med 2018;6:050312118799602.

3. Liu X, Zhou J, Chen L, et al. Impact of COVID-19 epidemic on live online dental continuing education. Eur J Dental Educ 2020;24:786-9.

4. Abidah A, Hidaayatullaah HN, Simamora RM, et al. The impact of Covid-19 to Indonesian education and its relation to the philosophy of "Merdeka Belajar". Stud Philos Sci Educ 2020;1:38-49.

5. Carlson SF. Cardiopulmonary resuscitation in schools: School nurses' perceptions of barriers and recommendations for integration. Phoenix: University of Phoenix; 2017.

6. Smereka J, Szarpak L, Czekajlo M, et al. The TrueCPR device in the process of teaching cardiopulmonary resuscitation: A randomized simulation trial. Medicine 2019;98:e15995.

7. Sarin-Gulian L, Espinoza J, Lee TC, et al. Development and evaluation of a tele-education program for neonatal ICU nurses in Armenia. J Pediatr Nurs 2020:57:e9-14.

8. Pivač S, Gradišek P, Skela-Savič B. The impact of cardiopulmonary resuscitation (CPR) training on schoolchildren and their CPR knowledge, attitudes toward CPR, and willingness to help others and to perform CPR: mixed methods research design. BMC Public Health 2020;20:915.

9. Moon H, Hyun HS. Nursing students' knowledge, attitude, self-efficacy in blended learning of cardiopulmonary resuscitation: a randomized controlled trial. BMC Med Educ 2019;19:414.
10. Hernández-Padilla J, Suthers F, Fernández-Sola C, et al. Development and psychometric assessment of the basic resuscitation skills self-efficacy scale. Eur J Cardiovasc Nurs 2016;15:e108.

11. Akhu-Zaheya LM, Gharaibeh MK, Alostaz ZM. Effectiveness of simulation on knowledge acquisition, knowledge retention, and self-efficacy of nursing students in Jordan. Clin Simulat Nurs 2013;9:e335-42

12. Na JU, Lee TR, Kang MJ, et al. Basic life support skill improvement with a newly designed renewal program: cluster randomized study of small-group-discussion method versus practice-whilewatching method. Emerg Med J 2014;31:964-9.

13. Park JY, Woo CH, Yoo JY. Effects of blended cardiopulmonary resuscitation and defibrillation e-learning on nursing students' selfefficacy, problem solving, and psychomotor skills. Comput Inform Nurs 2016;34:272-80.

14. Chien CY, Fang SY, Tsai LH, et al. Traditional versus blended CPR training program: A randomized controlled non-inferiority study. Sci Rep 2020;10:1-8.

15. Drummond D, Delval P, Abdenouri S, et al. Serious game versus online course for pretraining medical students before a simulationbased mastery learning course on cardiopulmonary resuscitation: A randomised controlled study. Eur J Anaesthesiol 2017;34:836-844.

16. DeFilippis EM, Ranard LS, Berg DD. Cardiopulmonary resuscitation during the COVID-19 pandemic: A view from trainees on the front line. Circulation 2020;141:1833-5.

17. Napp A, Kosan J, Hoffend C, et al. Implementation of basic life support training for school children: Online education for potential instructors? Results of a cluster randomised, controlled, non-inferiority trial. Resuscitation 2020;152:141-8.

18. Nord A, Svensson L, Claesson A, et al. The effect of a national web course "Help-Brain-Heart" as a supplemental learning tool before CPR training: a cluster randomised trial. Scand J Trauma Resusc Emerg Med 2017;25:93.

19. Johnson AL. Exploration of factors affecting the self-efficacy of asynchronous online learners: a mixed methods study. Blacksburg: Virginia Tech; 2017.

20. Boada I, Rodriguez-Benitez A, Thio-Henestrosa S, et al. How the gender of a victim character in a virtual scenario created to learn CPR protocol affecting student nurses' performance. Comput Methods Programs Biomed 2018;162:233-41.

21. Tobase L, Peres HH, Gianotto-Oliveira R, et al. The effects of an online basic life support course on undergraduate nursing students' learning. Int J Med Educ 2017;8:309.

22. Twohig CJ, Singer B, Grier G, et al. A systematic literature review and meta-analysis of the effectiveness of extracorporeal-CPR versus conventional-CPR for adult patients in cardiac arrest. J Intensive Care Soc 2019;20:347-57.

23. Lau Y, Nyoe RS, Wong SN, et al. Effectiveness of digital resuscitation training in improving knowledge and skills: A systematic review and meta-analysis of randomised controlled trials. Resuscitation 2018;131:14-23.

24. Zhou T, Huang S, Cheng J, et al. The distance teaching practice of combined mode of massive open online course micro-video for interns in emergency department during the COVID-19 epidemic period. Telemed J E Health 2020;26:584-8.

25. Nori JM, Saghafinia M, Motamedi MK, et al. CPR training for nurses: how often is it necessary? Iranian Red Crescent Med J 2012;14:104.

26. Nas J, Thannhauser J, Vart P, et al. Rationale and design of the Lowlands Saves Lives trial: a randomised trial to compare CPR quality and long-term attitude towards CPR performance between face-to-face and virtual reality training with the Lifesaver VR app. BMJ Open 2019;9:e033648. 